\title{
Liter per Day per Milligram per Kilogram
}

National Cancer Institute

\section{Source}

National Cancer Institute. Liter per Day per Milligram per Kilogram. NCI Thesaurus. Code C120729.

A unit of concentration equal to liter per day divided by milligram per kilogram. 